\title{
Residual Stress Consideration in Fatigue Damage of Offshore Wind Turbine Monopiles: To Be or Not to Be?
}

\author{
Adelani A. Oyeniran¹, Duabari S. Aziaka² \\ ${ }^{1}$ Department of Advanced Mechanical Engineering, Cranfield University, Bedfordshire, UK \\ ${ }^{2}$ Centre for Propulsion Engineering, Cranfield University, Bedfordshire, UK \\ Email: aaoyeniran@gmail.com,d.aziaka@cranfield.ac.uk
}

How to cite this paper: Oyeniran, A.A. and Aziaka, D.S. (2020) Residual Stress Consideration in Fatigue Damage of Offshore Wind Turbine Monopiles: To Be or Not to Be? World Journal of Mechanics, 10 , 39-52.

https://doi.org/10.4236/wjm.2020.104004

Received: March 19, 2020

Accepted: April 19, 2020

Published: April 22, 2020

Copyright $\odot 2020$ by author(s) and Scientific Research Publishing Inc. This work is licensed under the Creative Commons Attribution International License (CC BY 4.0).

http://creativecommons.org/licenses/by/4.0/

\begin{abstract}
The purpose of this paper was to investigate the impact of residual stresses on fatigue damage of offshore wind turbine monopiles by numerical analysis approach using ABAQUS software, a finite element analysis (FEA) tool. Three monopile models with the same dimension (within standard range) have been developed in ABAQUS and partitioned circumferentially into equal rings. Longitudinal partitions have been rotated through $180^{\circ}$ as obtainable in practice. Characteristic loads typical of a real life offshore wind turbine environment have been applied to all three models, with tensile and compressive residual stresses applied as additional loads at the critical weld region to the first and second models while the third model had no additional load. With zero boundary conditions applied in all six degrees of freedom, the simulation has been run for $10^{7}$ cycles of wind and wave loads as recommended in standards in each case. Stress results obtained from the critical weld region in the three models showed that the presence of tensile residual stresses equal to the material yield stress contributed a maximum $0.05 \%$ to fatigue damage of the monopile when compared with results from the model with no residual stress while the presence of compressive residual stresses with the magnitude of the yield stress of the material caused a gain of $0.06 \%$ in fatigue life by similar comparison, indicating negligible contribution of residual stresses to the stress build up in the critical weld region, thus suggesting that the magnitude of the residual stress as high as the yield stress of the material of the monopile is not large enough to cause the monopile to open up in the axial direction.
\end{abstract}

\section{Keywords}

Concentrated Force, Characteristic Loads, Post-Weld Heat Treatment, S-N 
Curve, Superposition

\section{Introduction}

Climate change, a global phenomenon arising from the increase in levels of carbon dioxide $\left(\mathrm{CO}_{2}\right)$ and other greenhouse gases due to human activity, has threatened human existence over the years. In response to this is a switch from conventional coal-powered plant to clean energy which has been embraced by many countries in the world [1].

In recent years, there has been exponential growth in the use of offshore wind farms to produce clean and renewable energy. While there are several foundation types used in shallow waters, the monopile is the most widely used as it accounts for about $75 \%$ of offshore wind turbine (OWT) installations in water depths up to $40 \mathrm{~m}$ [2] [3]. These monopiles are a single large-diameter manufactured steel tubes which penetrate the seabed and have outer diameters of up to $7.5 \mathrm{~m}$, a wall thickness of up to $150 \mathrm{~mm}$ and penetration depths ranging from 15 to $30 \mathrm{~m} \mathrm{[3].} \mathrm{The} \mathrm{monopile} \mathrm{geometry} \mathrm{is} \mathrm{defined} \mathrm{by} \mathrm{three} \mathrm{variables} \mathrm{viz;} \mathrm{diame-}$ ter, wall thickness and embedded length [4]. The monopile bears the loads (forces) of the rotor-nacelle assembly, the tower, work platform as well as the transition piece. All these constitute the vertical loads (axial loads) acting on the monopile. Other loads (forces) acting on the monopile are the aerodynamic and hydrodynamic loads, considered as frequency-dependent lateral loads. These lateral loads are generally larger than the axial loads, cause bending and hence, more critical than the vertical loads in monopiles as they control the serviceability limit state of the whole structure [3].

The manufacturing process used to produce OWT monopiles is rolling. Thick structural steel plates are rolled and welded in a longitudinal direction to form rings while these rings are subsequently welded circumferentially, thus forming monopiles [2]. Both rolling and welding processes are quite aggressive and introduce some residual stresses in the fabricated monopile [5]. These residual stresses can be quite beneficial (if compressive) or destructive (if tensile) to the OWT monopile [6]. One method to reduce or eliminate this residual stress, post-weld heat treatment (PWHT), is seldom performed on monopiles due to size and cost-related issues [7], contrary to what is advised in the offshore standards [8]. It is, therefore, a subject of debate whether residual stresses should be considered in structural integrity assessment of offshore wind monopiles.

Schajer, G [9] emphasized that residual stresses must be considered during engineering design just as stresses due to external loading and should not be ignored, as is often the case. Lu, J [10] supported the position of Schajer, G., using the principle of superposition of stresses and claimed that the real stress acting on a sample is an addition of both the applied stress as well as residual stress in the sample. Jacob, A, et al. [11] analysed a welded mock-up fabricated using a 
typical double- $\mathrm{V}$ welding procedure as well as a compact tension (CT) specimen and maintained that the residual stress effects were quite impactful on the fatigue damage, stressing that its neglect could lead to inaccurate estimation of fatigue life. Contrary to these schools of thought, offshore design standards [12] recommend that the residual stresses should be ignored. This work is thus important because mistreatment of residual stresses in offshore wind turbine monopiles could lead to underestimation or overestimation of fatigue life, with the latter having a tendency to cause catastrophic failure. Therefore, does the current industry practice with respect to residual stresses as recommended by the offshore design standards pose any fatigue failure risk to offshore wind turbine monopiles?

This work is therefore aimed at investigating the contribution of residual stresses to fatigue damage in OWT monopile foundations by numerical analysis as a way to determining a possible factor of shift in the S-N curve due to these residual stresses.

\section{Methodology}

A numerical analysis has been performed in this work in order to estimate the contribution of residual stresses to fatigue damage in offshore wind turbine monopiles. The ABAQUS FEA tool has been used to carry out simulation on three different models of the offshore wind turbine monopile. This FEA tool is a software suite for finite element analysis and computer-aided engineering. Since it has been reported that the highest residual stress that can be present in any engineering member is equivalent to the yield stress of the material [13], and that these residual stresses could be either tensile (producing a damaging effect by increasing the effective stress on the member, thereby reducing the fatigue life of the monopile) or compressive (producing a beneficial effect by reducing the effective stress on the member, thereby increasing the fatigue life of the monopile), three models have been developed in ABAQUS, one having all characteristic loads typical of an offshore wind turbine environment with the highest possible tensile residual stress, another having all characteristic loads typical of an offshore wind turbine environment with the lowest possible compressive residual stress, while a last model which had no residual stress but only offshore wind turbine environment characteristic loads were developed.

The simulation was performed for $10^{7}$ cycles of wave load as specified in the offshore design standards [12]. This was applied as a lateral load on the monopile models. Other loads applied on the monopile model, typical of a real life offshore wind monopile environment, were weight load (self-weight) applied as gravity acting downwards, vertical loads (comprising weights of tower, nacelle and rotor blades) applied as pressure on the top edge, horizontal load (aerodynamic load) applied as a concentrated force at a point on the top edge above sea water level and $\pm 355 \mathrm{MPa}$ residual stresses (corresponding to the worst/best case scenario of residual stresses) applied at the point where maximum bending is 
expected (closest weld to seabed) in the dominant Z-direction. The flow chart in Figure 1 below presents this methodology in a condensed form.

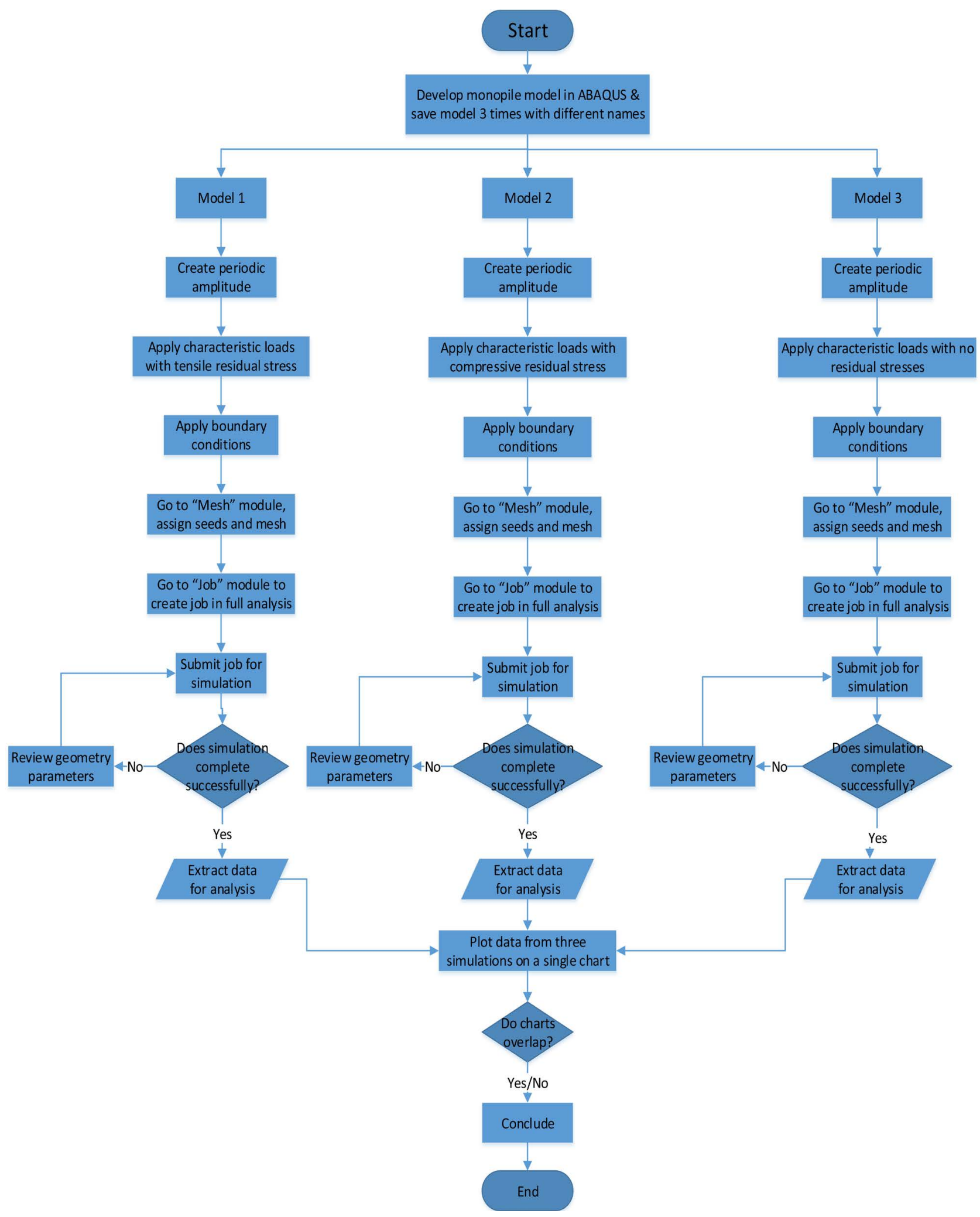

Figure 1. Flowchart showing the simulation steps. 


\section{Results and Discussions}

This section presents an evaluation of the finite element analysis by comparing the post-processing results from the three load cases under investigation in order to determine the contribution of residual stresses to the fatigue damage of offshore wind turbine monopiles.

\subsection{Application of Weight Load (Self-Weight) on the Monopile}

As stated earlier, one of the loads applied in this analysis is the weight of the monopile itself. Static analysis was carried out in the FEA simulation to ascertain the impact of the self-weight only on the monopile before applying other loads. Fundamentally, when an object is placed on a surface, it exerts its weight on the surface on which it is placed by creating a reaction force at the point of contact between the object and the surface. This has been demonstrated in this work by applying only the self-weight of the monopile using the gravity method and running the static analytic FEA simulation. Theoretically, it is generally known that weight, $\mathrm{W}$, of an object is the force (load in this case) of gravity acting on the object and defined by mass, $\mathrm{m}$, times the acceleration of gravity, g, i.e. $\mathrm{W}=\mathrm{mg}$. Also, density is mass divided by volume. Therefore, by defining both material density as a mechanical elastic property and the acceleration of gravity in ABAQUS, the weight of the monopile can be determined and used in the analysis, thus justifying the use of this gravity method to apply self-weight.

The figure below shows the result of the self-weight application to the monopile geometry.

It can be observed from Figure 2 that the weight of the monopile generated a non-zero reaction force only towards the end of the monopile at the region

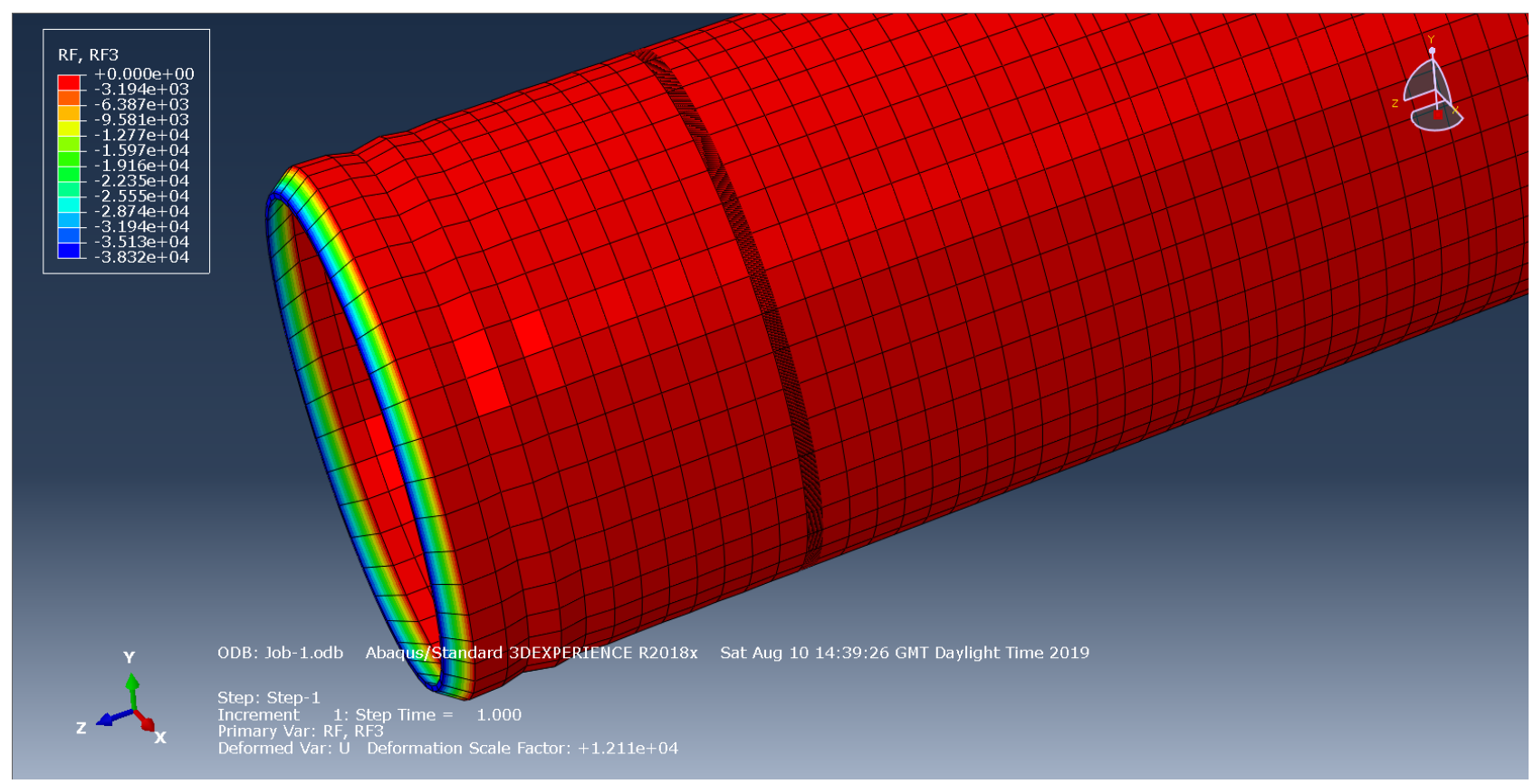

Figure 2. Vertical reaction force due to self-weight only. 
where the boundary condition was applied. This region represents the contact surface between the monopile and the sea bed. Other regions on the monopile returned zero reaction force, as the red colour of the contour plot showed. Also, some deformation can be observed towards the end of the monopile as shown. This is because weight is a downward force (due to the force of gravity), hence the layers of materials in the sections before the deformed region exerts their weight on this deformed section. The deformation occurred because the weight exerted from upper elements exceeds the material load strength in this section.

Since stresses are due to forces (loads) and weight is a type of force, Figure 3 shows the stress distribution on the monopile due to application of self-weight only. As can be seen on the contour plot, the highest stress value is in the top region (red). This is so because there is a coupling applied between the reference point and the node sets on the top edge of the monopile. This region is also the region of application of the weight load, while the bottom section showed the lowest stress value. All stress values due to the weight load returned negative stresses (compressive) because the monopile layers lied on top of each other and compressed the layers below them towards the sea bed.

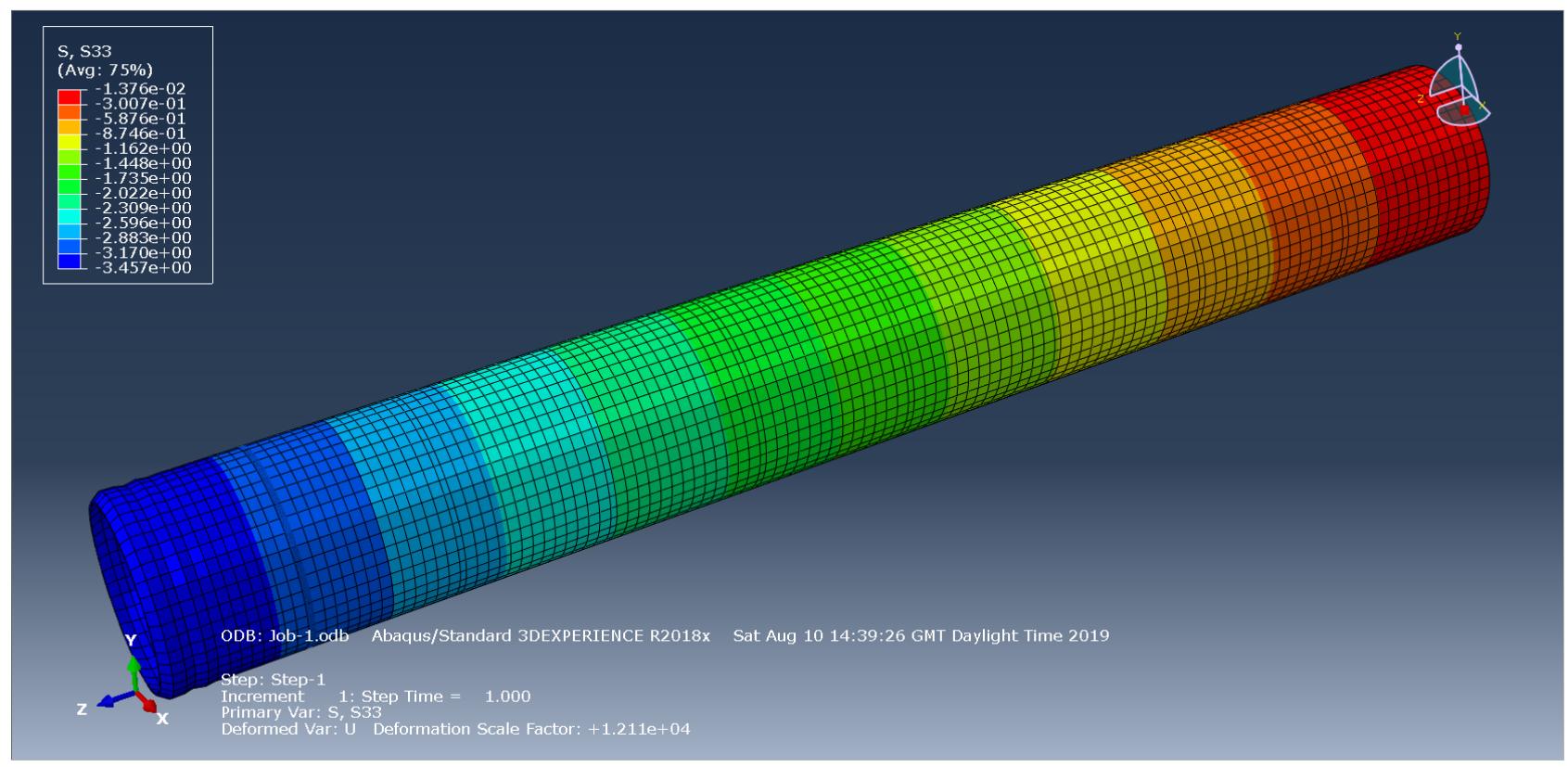

Figure 3. Stress distribution due to self-weight only.

\subsection{Tensile Residual Stress Analysis}

It has been reported that tensile residual stresses cause a destructive effect on engineering components. Also, the maximum tensile residual stress that could exist in any member is equal to $+S_{y}$, the yield stress of the material. Since the material of the monopile used in practice is mild steel, its yield stress value of $355 \mathrm{MPa}$ has been used in this analysis as reported in literature.

Therefore, in this work, the tensile residual stress value of $+355 \mathrm{MPa}$ has been applied at a node in the last weldment (weld closest to the sea bed). This is be- 
cause, given all loads acting on the monopile in the sea environment, bending tends to occur, the effect of which is maximum in the weld closest to the sea bed. Also, the value of $+355 \mathrm{MPa}$ used for the tensile residual stress assumes a worst-case scenario for this destructive residual stress. Thus, the last weldment is the region of investigation in this work as stresses in the dominant direction (Z-direction) were extracted from nodes along the circumference of this weld line as shown in Figure 4 below.

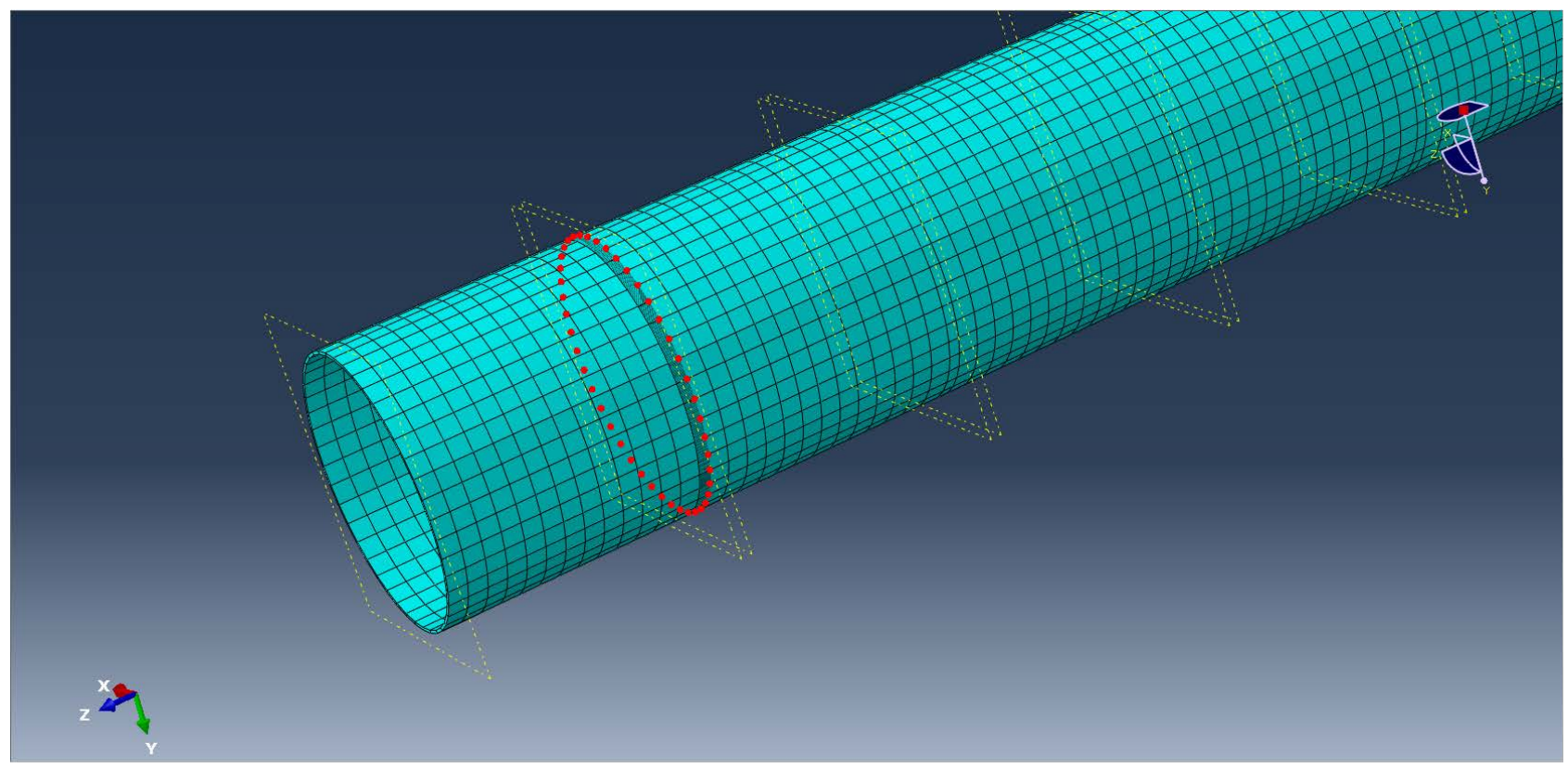

Figure 4. Node set for stress analysis.

The FEA simulation result for the application of all loads (wind, wave, WT, TRS and self-weight) with stresses extracted in the dominant Z-direction is as shown in Figure 5 below.

The contour plot (Figure 5 above) shows a maximum stress value of +300 $\mathrm{MPa}$ in the red region. Since this value is less than the yield strength of S355 steel, it therefore means that under the given loads, the monopile is still in the elastic region in the $\mathrm{Z}$-direction. That is to say that there is no permanent deformation and or fracture of the monopile.

The results of the stress distribution along the circumferential node-set, as shown in Figure 4 are presented in Figure 6 below.

As can be seen, Figure 6 above shows peak stress values of about $+300 \mathrm{MPa}$ and $-300 \mathrm{MPa}$ respectively along the critical weld region with a stress range of approximately $+600 \mathrm{MPa}$.

\subsection{Compressive Residual Stress Analysis}

In contrast to tensile residual stresses, compressive residual stresses have been found to be beneficial when present in engineering components as they tend to decelerate crack initiation and propagation. This has been extensively reported 


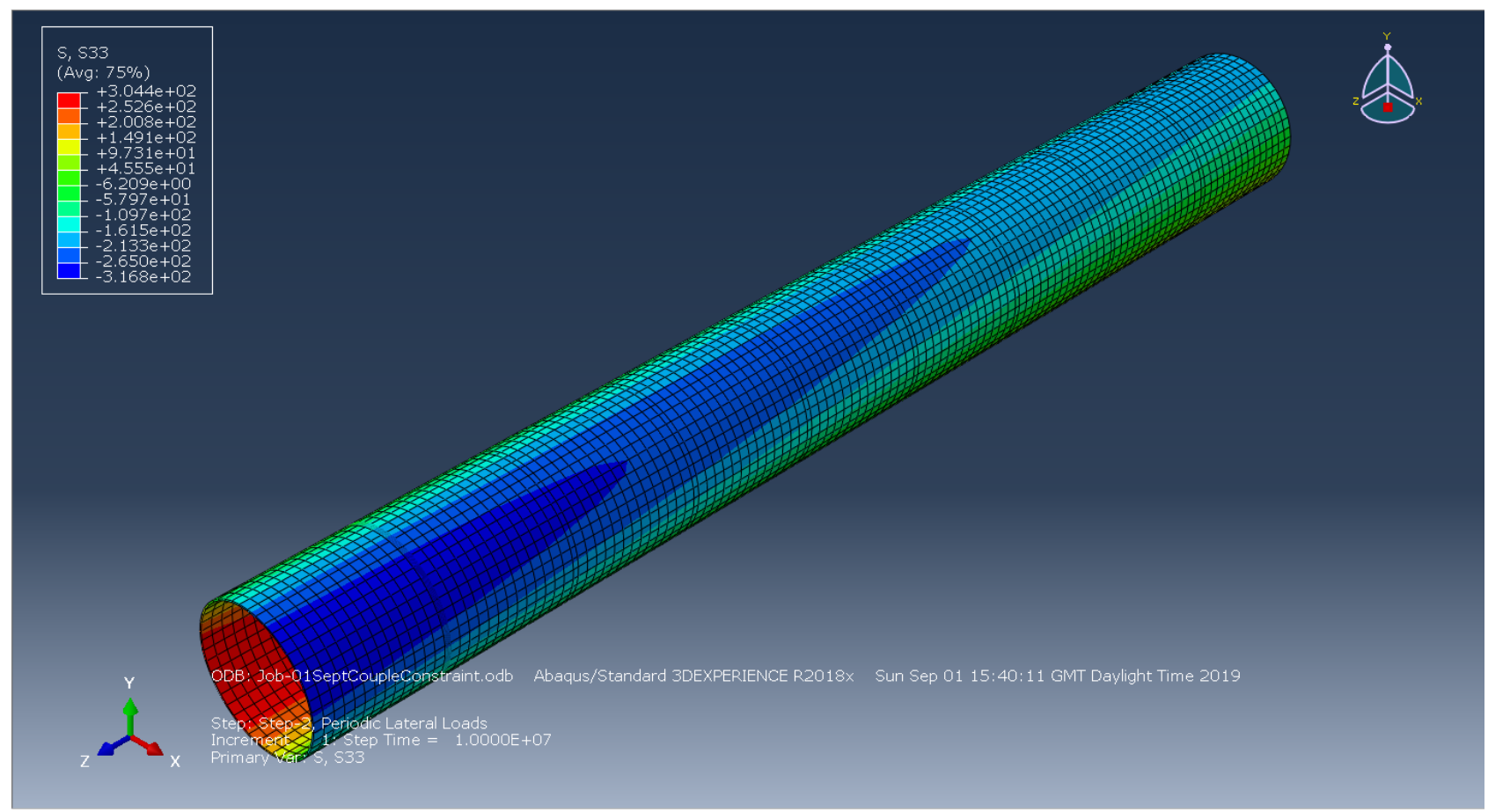

Figure 5. Contour plots for application of tensile residual stress and other characteristic loads.

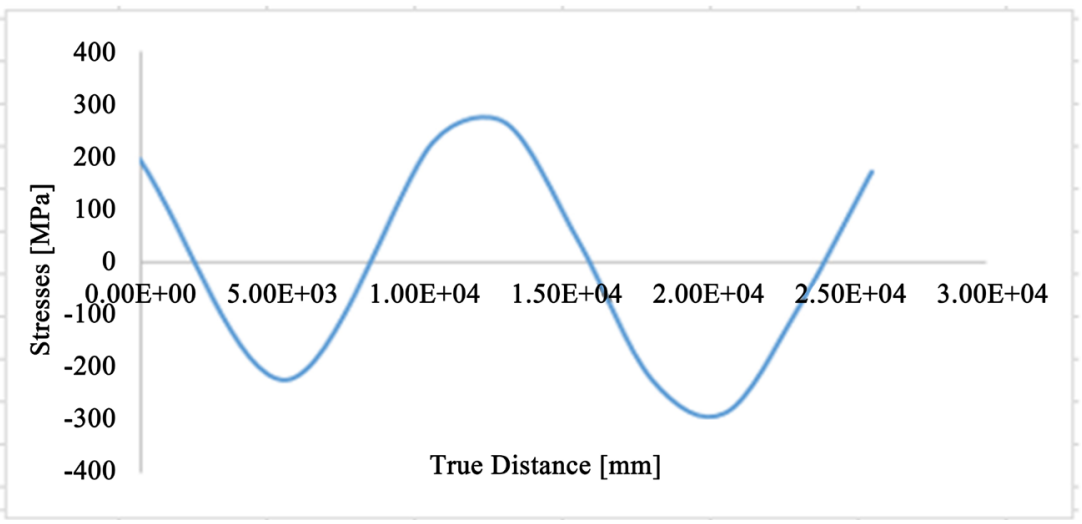

Figure 6. Stress distribution curve along the critical weld line (tensile case).

in the literature. Again, the minimum compressive residual stress that could be present in any engineering member is $-S_{y}$, the yield stress of the material.

Thus, the compressive residual stress value of $-355 \mathrm{MPa}$ has been applied at a node in the last weldment representing the critical weld line. This value represents the best case scenario achievable from the presence of compressive residual stresses in any engineering component.

Therefore, as stated above, stresses were extracted in the nodes along the critical weld line. Figure 7 below shows the contour plots.

The contour plot of Figure 7 shows peak stress values of about $+300 \mathrm{MPa}$ and $-320 \mathrm{MPa}$ in the dominant $\mathrm{Z}$-direction, respectively. These values are less than the yield stress of the material; hence the material is still within the elastic limit of deformation. The stress distribution along the critical weld line as extracted 


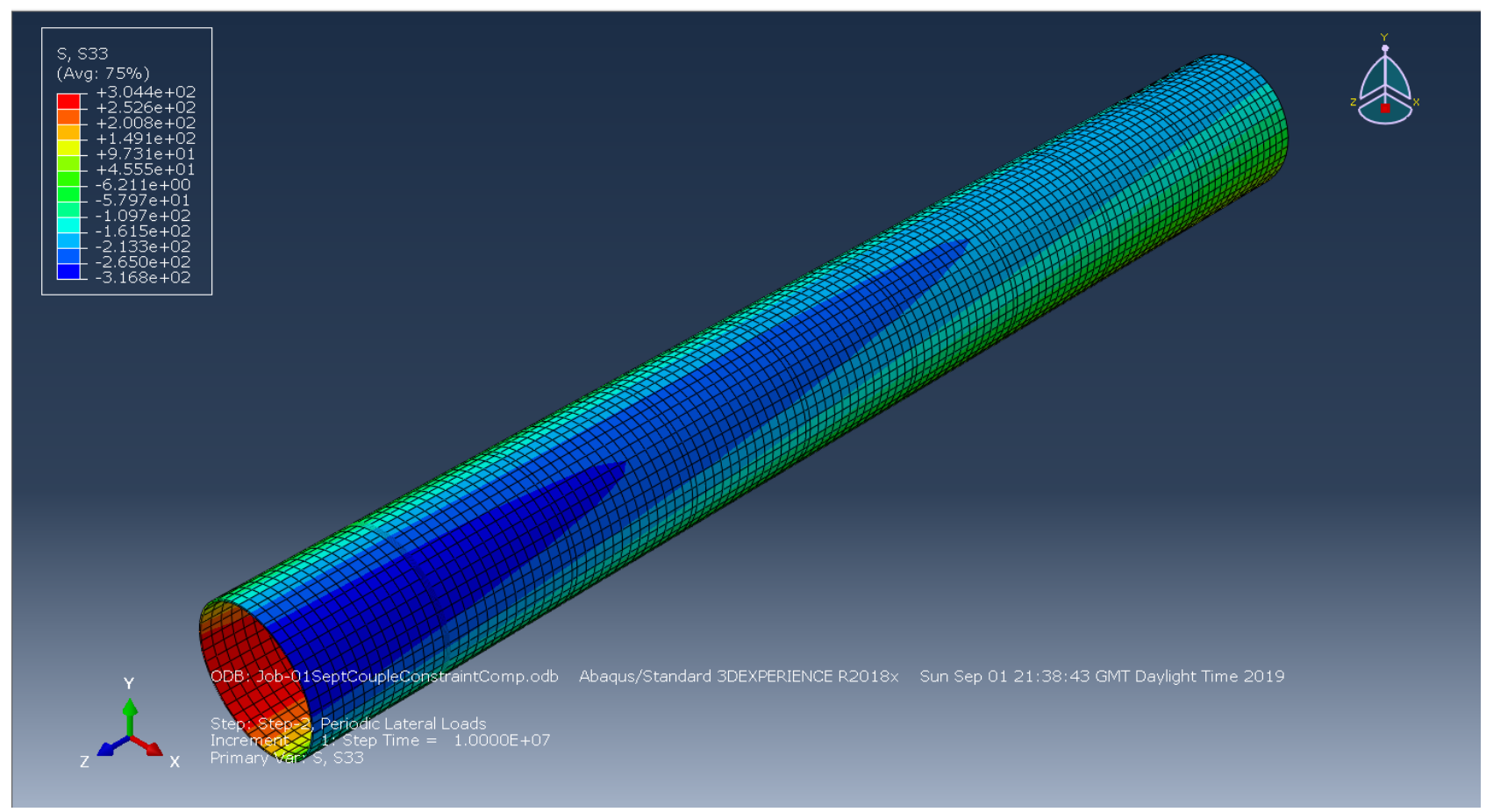

Figure 7. Contour plots showing an application of compressive residual stress and other characteristic loads.

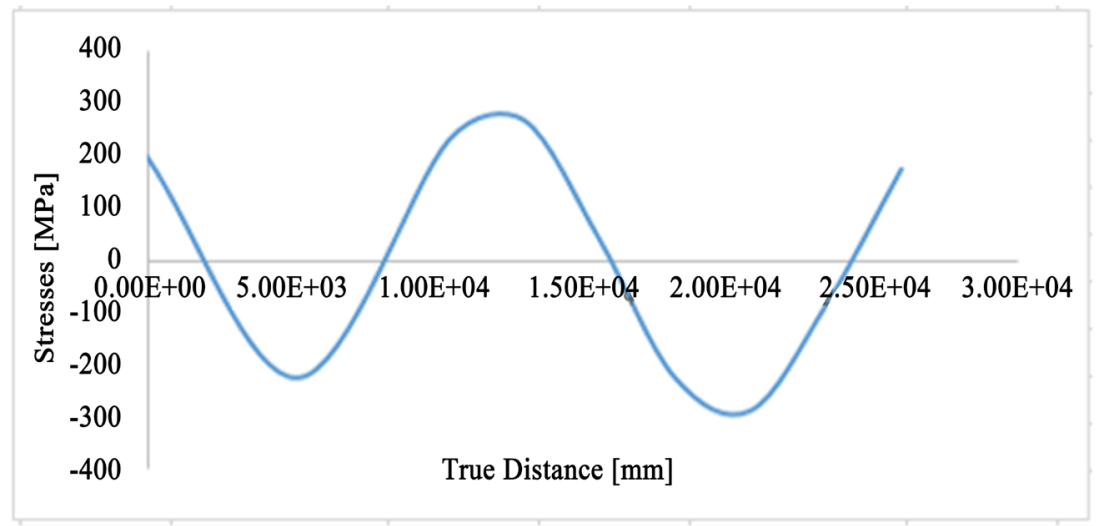

Figure 8. Stress distribution curve along the critical weld line (compressive case).

from the simulation of the compressive case is as shown in the following figure.

From Figure 8 above, the peak stresses are about $+300 \mathrm{MPa}$ and $-300 \mathrm{MPa}$ respectively, thus giving a stress range of about $+600 \mathrm{MPa}$ respectively, just like the tensile case discussed above.

\subsection{Analysis of the Monopile Model without Residual Stresses}

Similar analysis as was applied to the tensile and compressive models was also applied to the third model, i.e., the model without residual stresses. The figure below shows the contour plots for the FE simulation of the model without residual stresses.

From the displays of Figure 5, Figure 7 and Figure 9, it can be clearly seen that the three figures returned the same values for the stresses in the Z-direction. 


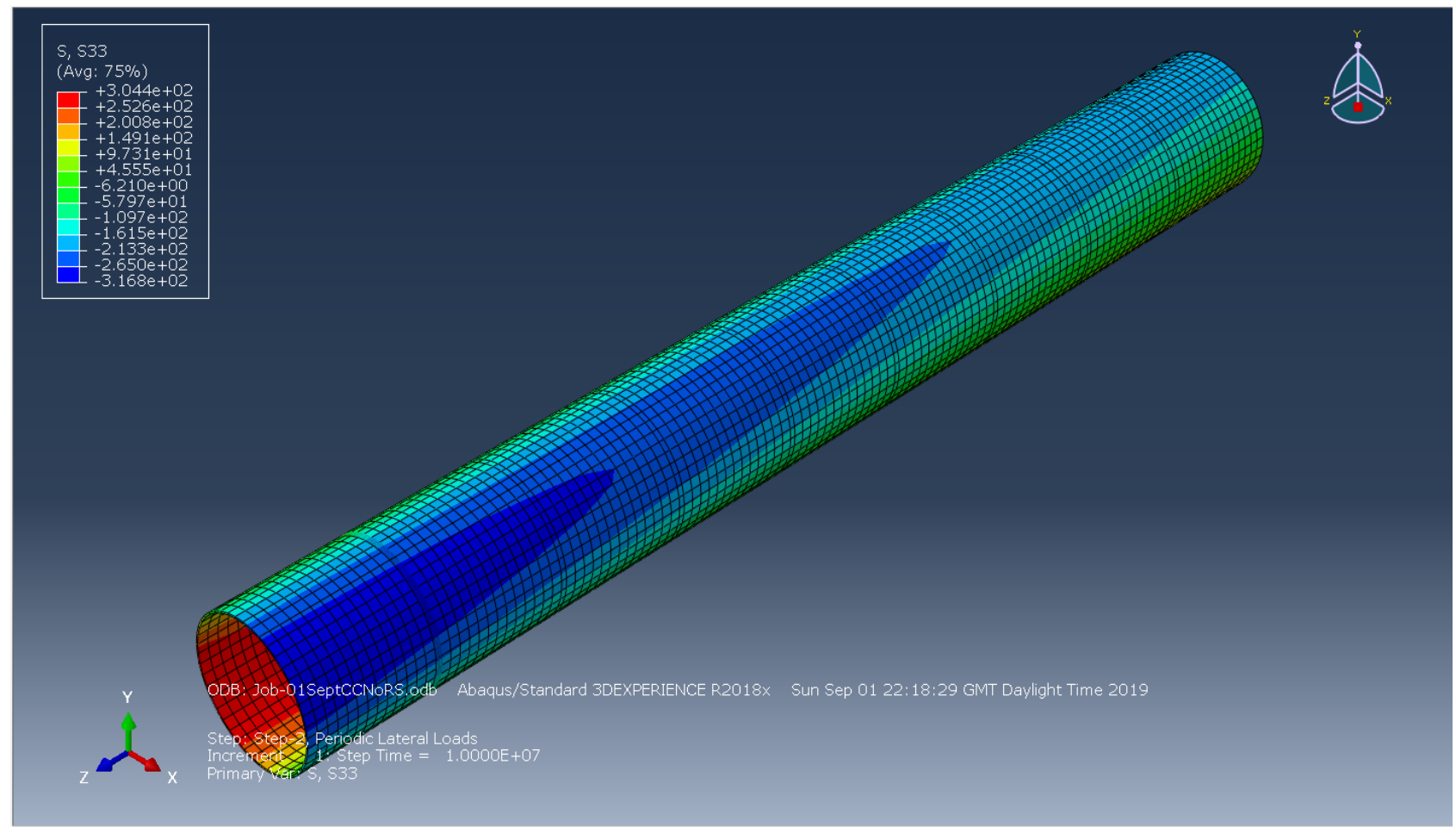

Figure 9. Contour plots showing the monopile model without residual stresses.

The stress profile for the critical weld region of the monopile model without residual stresses is as shown in Figure 10.

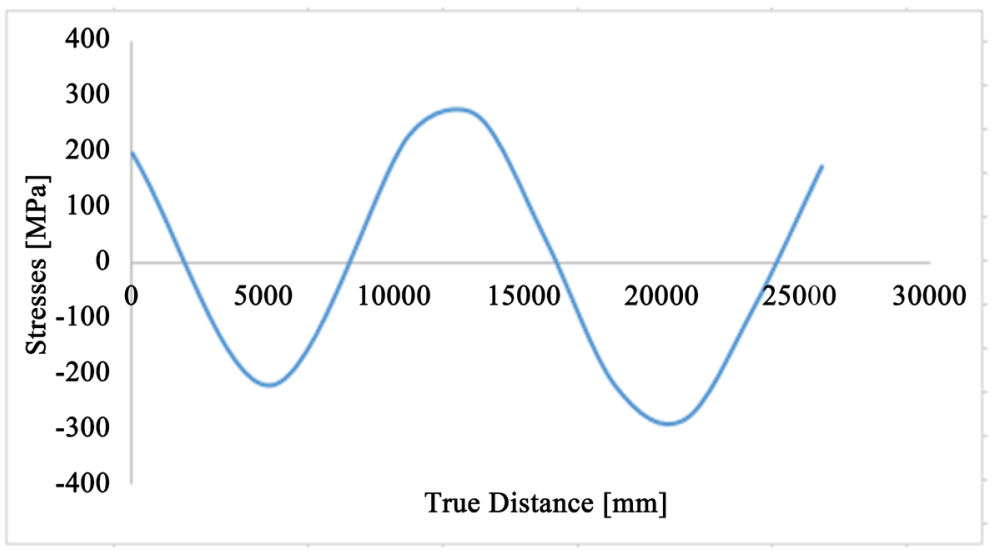

Figure 10. Stress distribution curve along the critical weld line without residual stresses.

Again, the stresses along the critical weld region range between $+300 \mathrm{MPa}$ and $-300 \mathrm{MPa}$ respectively, showing similar trends to the distribution of the models with residual stresses.

A critical analysis and review of the results from the three cases, i.e., loads with tensile residual stress, loads with compressive residual stress and loads without residual stresses revealed that the residual stresses did not affect the stress distribution along the critical weld line. The stress distribution for all load cases plotted on the same graph is as shown in Figure 11 below. 


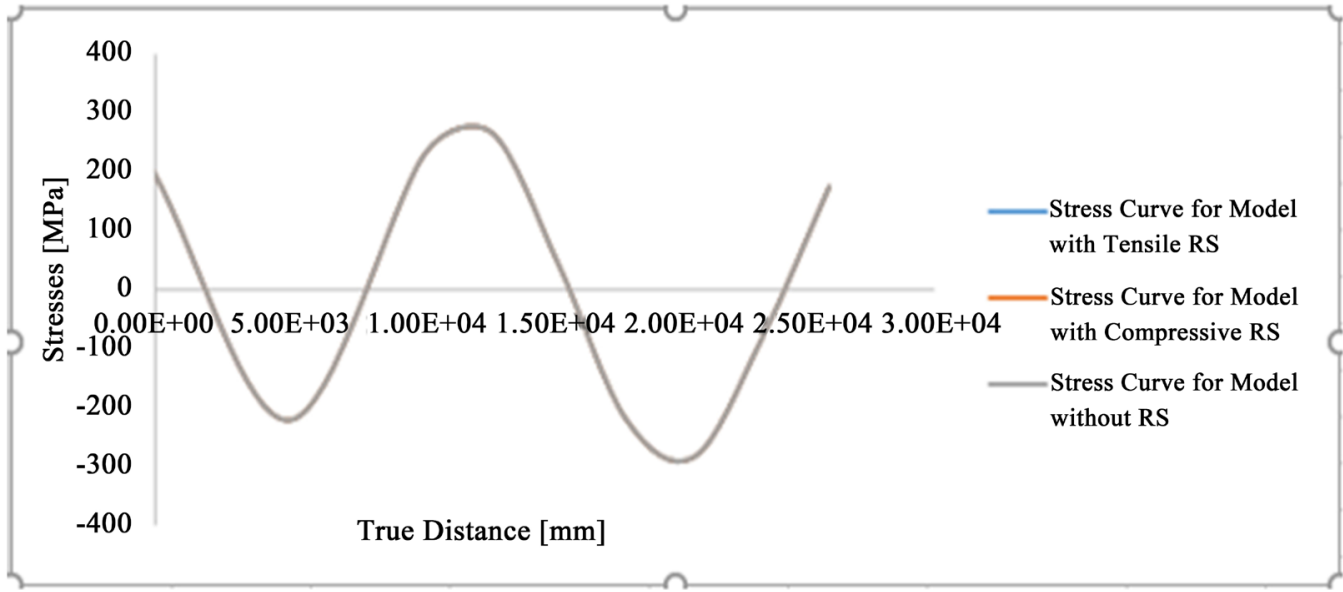

Figure 11. Stress profile showing all load cases plotted on the same graph.

All three load cases have been plotted on a single graph as the legend shows in Figure 11 above. It can be vividly seen that the three curves overlapped completely, thus showing only one visible curve. This means that the presence of tensile residual stress in the first case and compressive residual stress in the second case did not show any significant effect with respect to the outcome of the FEA simulation as compared to the case without any residual stress (tensile or compressive), even though the residual stresses (additional stresses) were applied in the Z-direction (the dominant stress direction). That is to say that the residual stress values are not large enough to contribute to the stresses in the axial direction. This is because the weight of the portion of the monopile above the critical weld region as well as the vertical loads (RNA, tower and self-weight) rest on the critical weld region under investigation, thus preventing it from opening up. It may, therefore, be necessary to conduct a sensitivity analysis of the results in order to predict its behaviour to changes in certain input parameters.

\subsection{Model Validity}

It has been widely reported that tensile residual stresses are harmful to engineering components as they accelerate crack initiation and can be as high as the yield stress of the material. Many works of literature have also emphasized the benefits of compressive residual stresses in decelerating crack initiation. It is therefore expected that the presence of tensile residual stress in an engineering component will increase the effective stress acting on the component to a value higher than the applied stress, in accordance with the principle of superposition. Similarly, when compressive residual stress is present in an engineering component, the effective stress acting on the component will be less than the applied stress. Hence, ignoring residual stress will mean that the effective stress is just equal to the applied stress.

The statements above have been satisfied with this work. That is, considering the output values, one can see that the tensile case has the highest stress values, followed by the results from the model without residual stress and lastly, the re- 
sults from the model with compressive residual stress. However, a critical evaluation of the values in terms of the small changes indicates that the residual stress is not large enough to cause the monopile to open up in the axial direction, thus suggesting that ignoring it has no significant impact on the fatigue life of offshore wind turbine monopiles. This submission is in agreement with the current industry practice and consistent with the offshore design standards DNVGL RP C203.

\section{Conclusions}

A numerical analysis which examined the effect of residual stresses on fatigue damage of offshore wind turbine monopile foundations has been carried out in this work. The material considered for the analysis is the S355 structural steel, as is obtainable in practice. A monopile model within the range of established monopile geometry has been built in ABAQUS where the best/worst case of residual stress (that is, the material yield stress) have been applied in the critical weld region (circumferential weld closest to the sea bed) as concentrated force along Z-direction, the dominant stress direction. In order to ascertain the contribution of residual stresses on the offshore wind turbine monopile fatigue damage, three different load cases have been examined, and these are characteristic loads with tensile residual stress, characteristic loads with compressive residual stress and characteristic loads only (i.e. without residual stresses).

The numerical results obtained from the FEA simulations have shown no significant contribution/effect when residual stresses are included in the analysis, indicating that the residual stress values up to the yield stress of the material are not sufficient enough to contribute to the fatigue damage of the offshore wind turbine monopile.

Therefore, the analysis has revealed that ignoring residual stresses during the monopile design process is conclusively a good practice as its inclusion has a negligible effect on fatigue damage of the offshore wind turbine monopile and poses no risk of catastrophic failure, which therefore implies that the S-N curve being used is in order.

\section{Recommendation for Further Studies}

As a recommendation for future work, it is suggested that welds should be modeled using a welding software such as AWI (Abaqus welding interface).

Also, Abaqus Aqua should also be used in an offshore analysis. These were not accessible at the time of conducting this work but are expected to give a more accurate result.

In addition, soil-pile interaction should be considered in the model for future analysis and results compared with a simplified approach as was used in this work.

It has also been reported that the SLIC Joint Industry Project to develop S-N curves characteristic of the offshore wind industry is ongoing as at when this 
work was done. It is therefore suggested that a more detailed fatigue analysis be conducted when a more detailed design is available.

\section{Conflicts of Interest}

The authors declare no conflicts of interest regarding the publication of this paper.

\section{References}

[1] Global Energy Monitor (2019) "New Report Global Slowdown in Coal Power..." [Online]. https://endcoal.org/2019/03/new-report-global-slowdown-in-coal-power-investmen t-continues-but-chinese-power-industry-pushes-for-hundreds-of-new-plants/

[2] Bocher, M., Mehmanparast, A., Braithwaite, J. and Shafiee, M. (2018) New Shape Function Solutions for Fracture Mechanics Analysis of Offshore Wind Turbine Monopile Foundations. Ocean Engineering, 160, 264-275.

https://doi.org/10.1016/j.oceaneng.2018.04.073

[3] Arshad, M. and O’Kelly, B.C. (2016) Analysis and Design of Monopile Foundations for Offshore Wind-Turbine Structures. Marine Georesources \& Geotechnology, 34, 503-525. https://doi.org/10.1080/1064119X.2015.1033070

[4] Arany, L., Bhattacharya, S., Macdonald, J. and Hogan, S.J. (2017) Design of Monopiles for Offshore Wind Turbines in 10 Steps. Soil Dynamics and Earthquake Engineering, 92, 126-152. https://doi.org/10.1016/j.soildyn.2016.09.024

[5] Wilbur, M.W. and Chao-Chien, H. (2007) Residual Stresses in Welded Structures, A Report of an Investigation Conducted by the Engineering Experiment Station. University of Illinois, Urbana.

[6] Munse, W.H. (1964) Fatigue of Welded Steel Structures.

[7] Khajeian, A., Mahmoudi, A.H. and Mehmanparast, A. (2019) Shot Peening Effects on Residual Stresses Redistribution of Offshore wind Monopile Multi-Pass Weldments. Marine Structures, 66, 106-120.

https://doi.org/10.1016/j.marstruc.2019.03.006

[8] Veritas, D.N. (2007) Fabrication and Testing of Offshore Structures.

[9] Schajer, G.S. (2013) Practical Residual Stress Measurement Methods. John Wiley \& Sons Ltd., New Jersey. https://doi.org/10.1002/9781118402832

[10] Jian, D.L. (1996) Handbook of Measurement of Residual Stresses for the Society for Experimental Mechanics (U.S). Fairmont Press, Lilburn, GA.

[11] Jacob, A., De Oliveira, J.A., Mehmanparast, A., Hosseinzadeh, F. and Berto, F. (2018) Should Residual Stresses Be Taken into Account in Structural Integrity Assessment of Offshore Monopiles? ASME 2018 37th International Conference on Ocean, Offshore and Arctic Engineering, Madrid, 17-22 June 2018. https://doi.org/10.1115/OMAE2018-78519

[12] DNVGL-RP-C203 (2016) Fatigue Design of Offshore Steel Structures.

[13] Maddox, S.J. (2011) Fracture and Fatigue of Welded Joints and Structures. 


\section{Nomenclature}

$\begin{array}{ll}\text { AWI } & \text { Abaqus Welding Interface } \\ \mathrm{CO}_{2} & \text { Carbon dioxide } \\ \text { CT } & \text { Compact Tension } \\ \text { DNVGL } & \text { Det Norske Veritas and Germanischer Lloyd } \\ \text { FE } & \text { Finite Element } \\ \text { FEA } & \text { Finite Element Analysis } \\ \text { GEM } & \text { Global Energy Monitor } \\ \text { OWT } & \text { Offshore Wind Turbine } \\ \text { PWHT } & \text { Post-Weld Heat Treatment } \\ \text { RNA } & \text { Rotor Nacelle Assembly } \\ \text { RP } & \text { Recommended Practice } \\ \text { RS } & \text { Residual Stress(es) } \\ \text { SLIC } & \text { Structural Lifecycle Industry Collaboration } \\ \text { S-N } & \text { Stress and associated Number of cycles to failure } \\ \text { S } & \text { Yield Stress } \\ \text { TRS } & \text { Tensile Residual Stress } \\ \text { WT } & \text { Wind Turbine }\end{array}$

